\title{
Using Four-Level NSVM Technique to Improve DVC Control of a DFIG Based Wind Turbine Systems
}

\author{
Habib Benbouhenni ${ }^{*}$, Zinelaabidine Boudjema², Abdelkader Belaidi ${ }^{1}$ \\ 1 Electrical Engineering Department, National Polytechnique School of Oran Maurice Audin, \\ LAAS Research Laboratory, BP. 1523 El M'Naouer 31000 Oran, Algeria \\ 2 Electrical Engineering Department, Hassiba Benbouali University, LGEER Research Laboratory, \\ Salem district 02000 Chlef, Algeria \\ *Corresponding author, e-mail: habib0264@gmail.com
}

Received: 23 December 2018, Accepted: 06 February 2019, Published online: 29 March 2019

\begin{abstract}
Traditional direct vector control (DVC) compositions which consist of proportional-integral (PI) regulators of a doubly fed induction generator (DFIG) driven have several disadvantages such as parameter variation problem, low dynamic performances and poor robustness. Therefore, based on examination of the DFIG model supplied by new modulation method, this work addresses a fourlevel space vector modulation (SVM) based on neural networks (NSVM). The conventional DVC control with SVM strategy has large ripples on the electromagnetic torque, harmonic distortion of rotor current, stator reactive and active powers developed by the DFIG-based wind turbine systems (WTSs). In order to resolve these problems, the DVC technique with NSVM strategy is proposed. Simulation results show the effectiveness of the proposed control technique especially in electromagnetic torque, power ripples and robustness against parameters variations.
\end{abstract}

\section{Keywords}

direct vector control, doubly fed induction generator, space vector modulation, neural space vector modulation, neural networks

\section{Introduction}

The main objective of this article is the studying of the four-level space vector modulation (4L-SVM) and fourlevel neural space vector modulation (4L-NSVM) strategies applied to the DFIG therefore; our work is organized as follows:

- The first part is devoted to the description and modeling of wind turbines based on physical equations responding operation.

- In the second part, we present a mathematical model of the DFIG, the model will simulate generator mode.

- The third is devoted to the study of the technical modulation strategy 4L-SVM and 4L-NSVM strategy of the DFIG.

\section{Turbine model}

The WT input power is given by $[1,2]$ :

$$
P_{\max }=0.5 \rho \pi R^{2} V_{\text {vent }}^{3} \text {. }
$$

$$
\begin{aligned}
& P_{m}=0.5 \cdot C_{p}(\lambda) \cdot \rho \pi R^{2} V_{\text {vent }}^{3} \\
& \lambda=\frac{R \cdot \Omega_{1}}{V_{1}} \\
& C_{p}(\beta, \lambda)=C_{1}\left(\frac{C_{2}}{\lambda_{i}}-C_{3} \cdot \beta C_{4}\right) \exp \left(\frac{-C_{5}}{\lambda_{i}}\right)+C_{6} \lambda \\
& \frac{1}{\lambda_{i}}=\frac{1}{\lambda+0.08 \beta}-\frac{0.035}{\beta^{3}+1}
\end{aligned}
$$

Where, $C_{1}=0.5176, C_{2}=116, C_{3}=0.4, C_{4}=5, C_{5}=21$, $C_{6}=0.0068$.

$\rho$ : The air density.

$V_{\text {vent }}:$ The wind speed $(\mathrm{m} / \mathrm{s})$.

$P_{\text {max }}:$ The maximum power in (watts).

$R$ : The radius of the turbine in (m).

$C_{p}$ : The aerodynamic coefficient of power.

$\lambda$ : The tip speed ratio.

$\beta$ : The blade pitch angle in a pitch-controlled wind turbine.

The mechanical power can be written as: 


\section{Modeling of the DFIG}

In the literature, the Park model of the DFIG is the widely used [3-5]. The equations of voltages and fluxes for the DFIG rotor and stator in Park orientation structure are given by:

$$
\left\{\begin{array}{l}
V_{d s}=R_{s} I_{d s}+\frac{d}{d t} \psi_{d s}-\omega_{s} \psi_{q s} \\
V_{q s}=R_{s} I_{q s}+\frac{d}{d t} \psi_{q s}-\omega_{s} \psi_{d s} \\
V_{d r}=R_{r} I_{d r}+\frac{d}{d t} \psi_{d r}-\omega_{r} \psi_{q r} \\
V_{q s}=R_{r} I_{q r}+\frac{d}{d t} \psi_{q r}-\omega_{r} \psi_{d r}
\end{array}\right.
$$

The rotor and stator flux can be expressed as:

$\left\{\begin{array}{l}\psi_{d s}=L_{s} I_{d s}+M I_{d r} \\ \psi_{q s}=L_{s} I_{q s}+M I_{q r} \\ \psi_{d r}=L_{s} I_{d r}+M I_{d s} \\ \psi_{q r}=L_{s} I_{q r}+M I_{q s}\end{array}\right.$.

The stator active and reactive powers can be written as:

$$
\left\{\begin{array}{l}
P_{s}=\frac{3}{2}\left(V_{d s} I_{d s}+V_{q s} I_{q s}\right) \\
Q_{s}=\frac{3}{2}\left(V_{q s} I_{d s}-V_{d s} I_{q s}\right)
\end{array} .\right.
$$

The torque is given by:

$$
\begin{aligned}
& T_{e}=p M\left(I_{d r} \cdot I_{q s}-I_{q r} \cdot I_{d s}\right) \\
& T_{e}=T_{r}+J \cdot \frac{d \Omega}{d t}+f \cdot \Omega
\end{aligned}
$$

$V_{d r}$ and $V_{q r}:$ is the rotor voltages.

$V_{q s}$ and $V_{d s}$ : is the stator voltages.

$I_{d r}$, and $I_{q r}$ : is the rotor currents.

$I_{d s}$ and $I_{q s}:$ is the stator currents.

$\psi_{d r}$ and $\psi_{q r}$ : is the rotor fluxes.

$\psi_{d s}$ and $\psi_{q s}$ : is the stator fluxes.

$L_{r}:$ is the inductance own rotor

$L_{s}:$ is the inductance own rotor

$M:$ is the mutual inductance.

$R_{r}$ : is the resistances of the rotor windings.

$R_{s}$ : is the resistances of the stator windings.

$\omega_{s}$ : is the electrical pulsation of the stator .

$\omega_{r}$ : is the electrical pulsation of the rotor.

$T_{r}:$ is the load torque.

$T_{e}:$ is the electromagnetic torque.

$\Omega:$ is the mechanical rotor speed.

$J:$ is the inertia.

$f:$ is the viscous friction coefficient.

$p:$ is the number of pole pairs.
$P_{s}:$ is the stator active power.

$Q_{s}:$ is the stator reactive power.

\section{Four-level NSVM inverter}

In modulation strategies, the space vector modulation (SVM) is widely used in control AC machine drives. This strategy is based on the principles of space vectors and requires the calculation of sector and angle $[6,7]$. However, this modulation strategy is detailed in [8-10]. In this work, we propose a new SVM modulation of four-level NPC inverter based on calculation of maximum and minimum of voltages. However, this strategy is detailed in [11, 12]. On the other hand, the advantage of the proposed SVM technique that it does not need to calculate the sector and angle, is simple to implement and produces a strong performance for the real-time feedback control. The SVM strategy block represents the four-level inverter model as shown in Fig. 1.

In order to improve the four-level SVM performances, a additional use of the artificial neural networks (ANN) is proposed. The principle of neural space vector modulation (NSVM) is similar to conventional SVM strategy. The difference is the use ANN to replace the hysteresis comparators. As shown in Fig. 2.

A neural network (NN) is newly getting increasing stress in drive control applications. The main advantage of the NN controller it is that is easy to implement the control and that it has the capability of generalization [13]. The block diagram of NN based hysteresis comparators is shown in Fig. 3. The structure of Layer 1 and layer 2 is shown in Fig. 4 and Fig. 5 respectively.

A summary of the convergence of the network obtained by using the value of the parameters is depicted in Table 1.

The four-level NSVM strategy gives more minimum of THD value, minimize power ripples, simple scheme and easy to implement compared to classical SVM.

$$
\left\{\begin{array}{c}
\psi_{s}=L_{s} I_{d s}+M I_{d r} \\
0=L_{s} I_{q s}+M I_{q r}
\end{array}\right.
$$

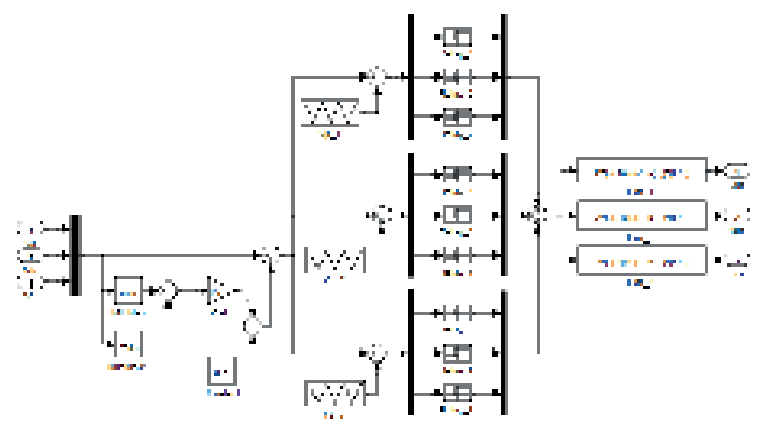

Fig. 1 Four-level SVM strategy 
Table 1 Parameters of the LM for hysteresis comparators

\begin{tabular}{lc}
\hline Parameters of the LM & Values \\
\hline Number of hidden layer & 08 \\
TrainParam.show & 1000 \\
TrainParam.eposh & 0.005 \\
TrainParam.Lr & \\
Coeff of acceleration of & \\
convergence (mc) &
\end{tabular}

Fig. 2 Four-level NSVM strategy

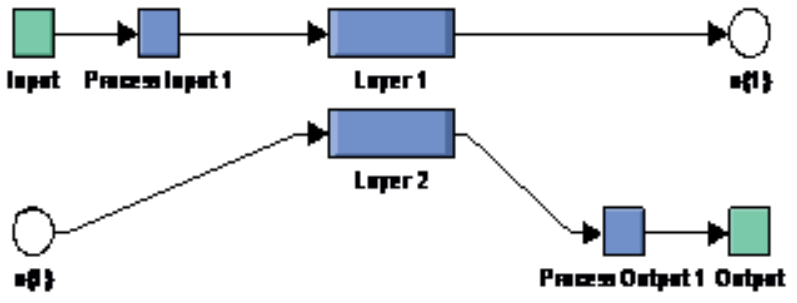

Fig. 3 The ANN controller

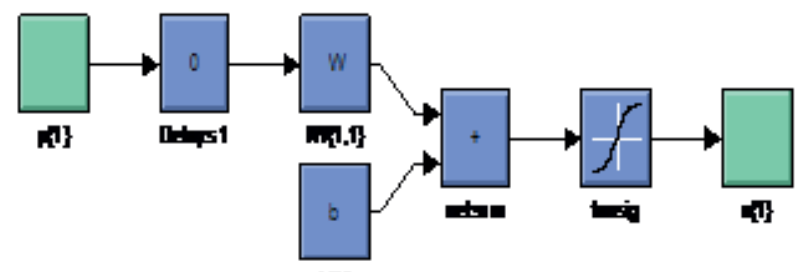

41\}

Fig. 4 Layer 1

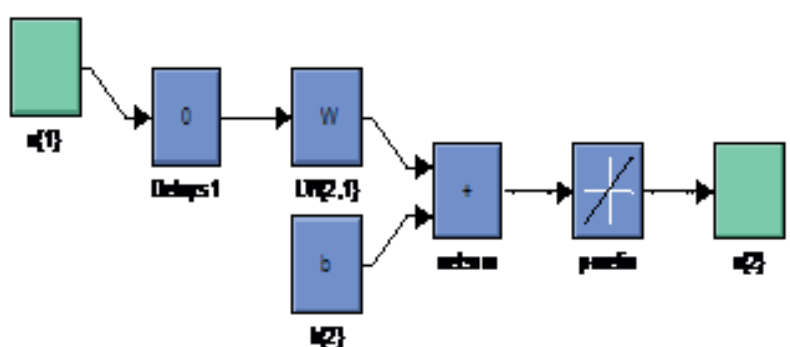

Fig. 5 Layer 2
The stator active and reactive powers and the electromagnetic torque are articulated in the Park frame as follows.

\section{The DFIG active and reactive powers control}

In this section, we choose a $d q$ reference frame coordinated with the stator flux (See Fig. 6) [14]. By setting the stator flux linkage vector aligned with d-axis, and neglecting Rs we can write [15-17]:

$\psi_{q s}=0, \psi_{d s}=\psi_{s}$

$P_{s}=-V_{s} \cdot \frac{M}{L_{s}} \cdot I_{q r}$

$Q_{s}=V_{s} \cdot \frac{V_{s}^{2}}{L_{s}} \frac{M}{L_{s}} \cdot I_{d r}$

$T_{e}=p \frac{M}{L_{s}} I_{q r} \psi_{d s}$.

Fig. 7 represents the direct vector control (DVC) technique of DFIG driven by a four-level NSVM inverter. However, DVC control is simple scheme and easy to implement. The interior block of DVC control is shown in Fig. 8.

\section{Simulation results}

The DVC control of a DFIG is implemented with simulation tools of MATLAB/Simulink. The DFIG $(1.5 \mathrm{MW})$ is

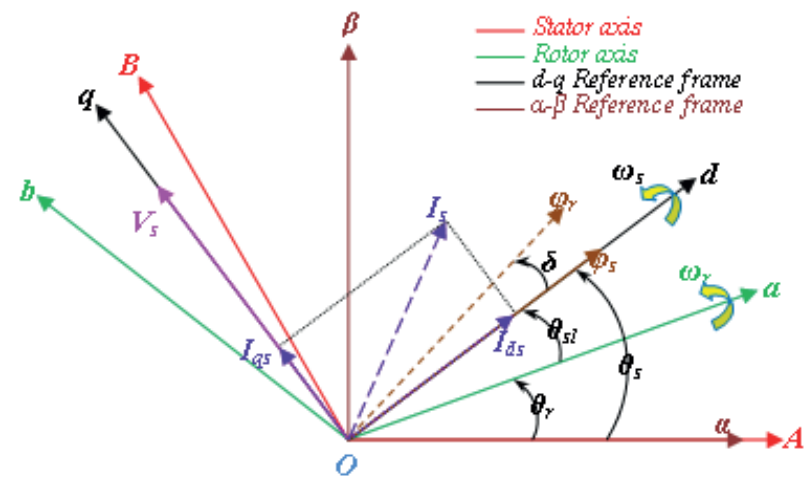

Fig. 6 Field oriented control strategy

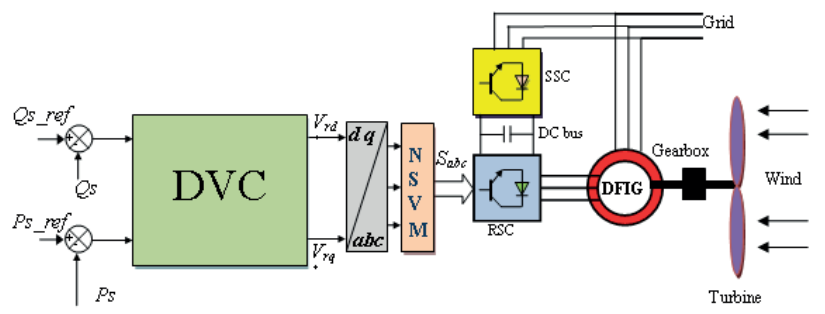

Fig. 7 Block diagram of DVC control with NSVM 
attached to a $398 \mathrm{~V} / 50 \mathrm{~Hz}$ grid. Parameters of the DFIG are given in Table 2 [18-20]. Both control techniques, DVC using 4L-SVM and DVC control using 4L-NSVM strategy are simulated and compared with respect to current harmonics distortion, reference tracking and robustness against DFIG parameter variations.

The DVC with neural space vector modulation reduces: the ripples on the stator active and reactive powers, on the electromagnetic torque and the THD value of rotor current.

\subsection{Reference tracking test (RTT)}

Figs. 9-16 show the obtained simulation results. As it's shown in Figs. 9-12, for the three DVC control strategies, the active stator power (Ps) and reactive stator power (Qs) tracks almost perfectly their references values $\left(\mathrm{Ps}_{\mathrm{ref}}\right.$ and $\left.\mathrm{Qs}_{\text {ref }}\right)$. Moreover, the DVC control using four-level NSVM technique minimized the powers ripples and electromagnetic torque (Te) ripple compared to the DVC using SVM strategy (See Figs. 12-14). Figs. 15-16 show the THD of

Table 2 The DFIG parameters

\begin{tabular}{lcc}
\hline Parameters & Rated Value & Unity \\
\hline P & 1.5 & $\mathrm{MW}$ \\
Vs & 398 & $\mathrm{~V}$ \\
Fs & 50 & $\mathrm{~Hz}$ \\
$\mathrm{P}$ & 2 & \\
Rs & 0.012 & $\Omega$ \\
Rr & 0.021 & $\Omega$ \\
Ls & 0.0137 & $\mathrm{H}$ \\
Lr & 0.0136 & $\mathrm{H}$ \\
M & 0.0135 & $\mathrm{H}$ \\
$\mathrm{J}$ & 1000 & $\mathrm{Kg} \mathrm{m}$ \\
$\mathrm{f}$ & 0.0024 & $\mathrm{Nm} . \mathrm{s} / \mathrm{rad}$ \\
\hline
\end{tabular}

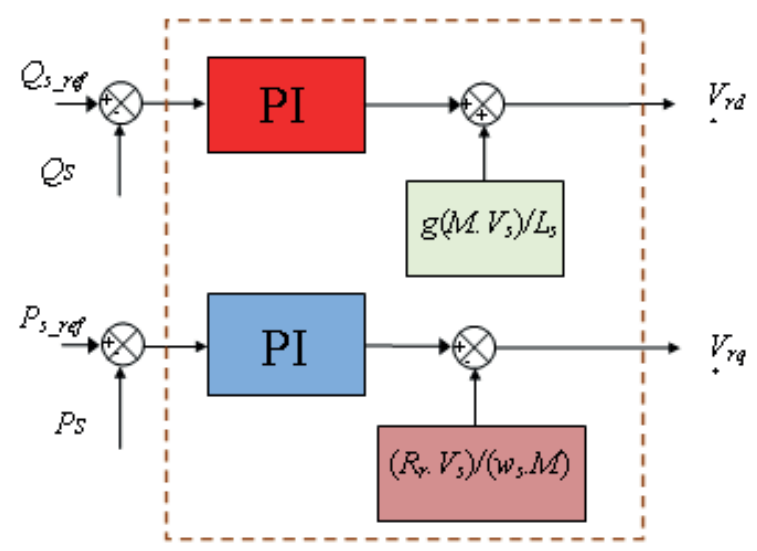

Fig. 8 Structure of DVC control scheme rotor current of the doubly fed induction generator for both DVC control schemes. It can be clearly observed that the THD value is minimized for DVC using four-level NSVM strategy (THD $=0.50 \%$ ) when compared to DVC using SVM $(\mathrm{THD}=0.65 \%)$

\subsection{Robustness test (RT)}

In this section, the nominal value of the $R_{r}$ and $R_{s}$ is multiplied by 2 , the values of inductances $L_{s}, M$, and $L_{r}$ are multiplied by 0.5 . Simulation results are presented in Figs. 17-24. As it's shown by these figures, these variations present an apparent effect on the reactive stator power, stator active power, and electromagnetic torque curves and that the effect appears more significant for the DVC using SVM technique compared to DVC using four-level NSVM (See Figs. 20-22).

The THD value of rotor current in the DVC using 4L-NSVM strategy has been minimized significantly (See Figs. 23-24). Table 3 shows the comparative analysis of

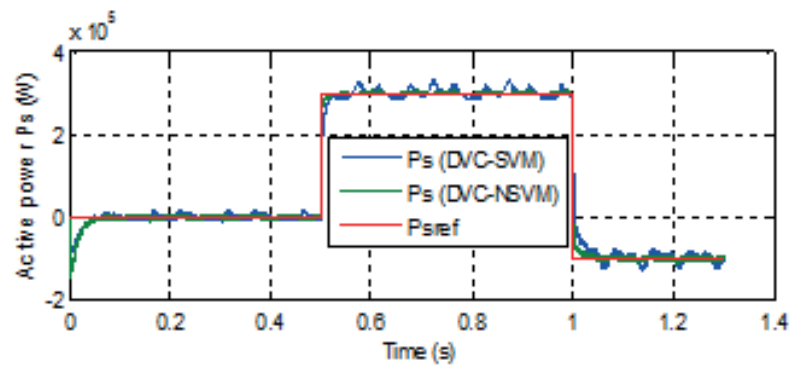

Fig. 9 Active power (RTT)

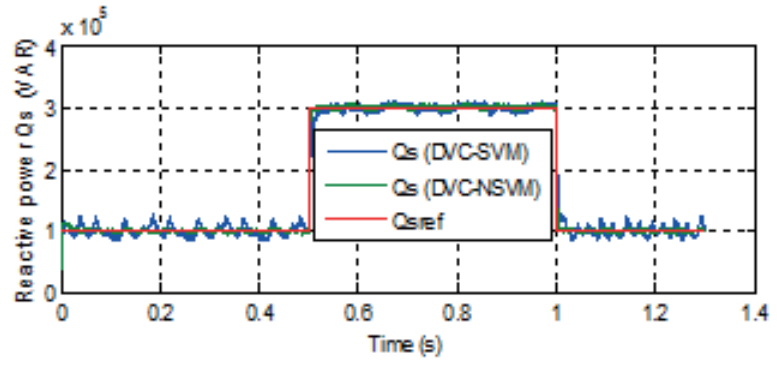

Fig. 10 Reactive power (RTT)

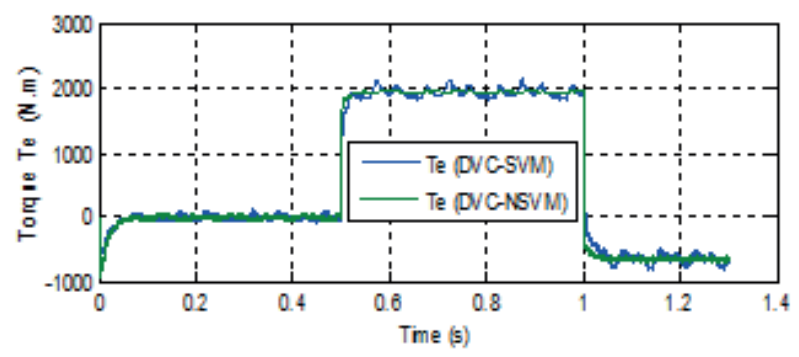

Fig. 11 Electromagnetic torque (RTT) 


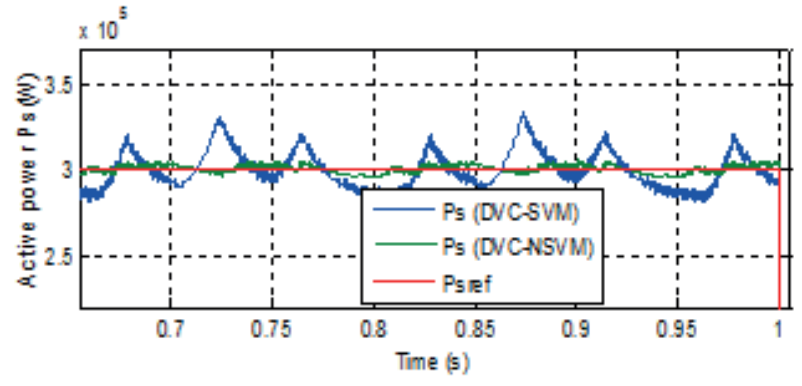

Fig. 12 Zoom in the active power (RTT)

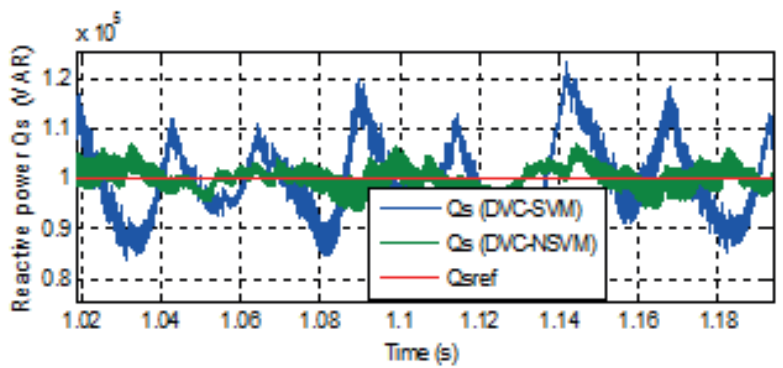

Fig. 13 Zoom in the reactive power (RTT)

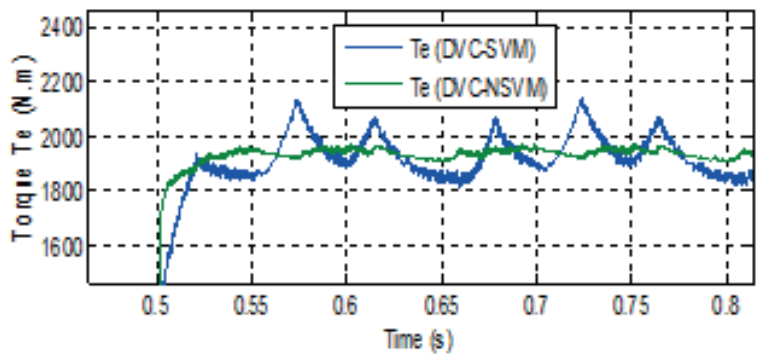

Fig. 14 Zoom in the electromagnetic torque (RTT)
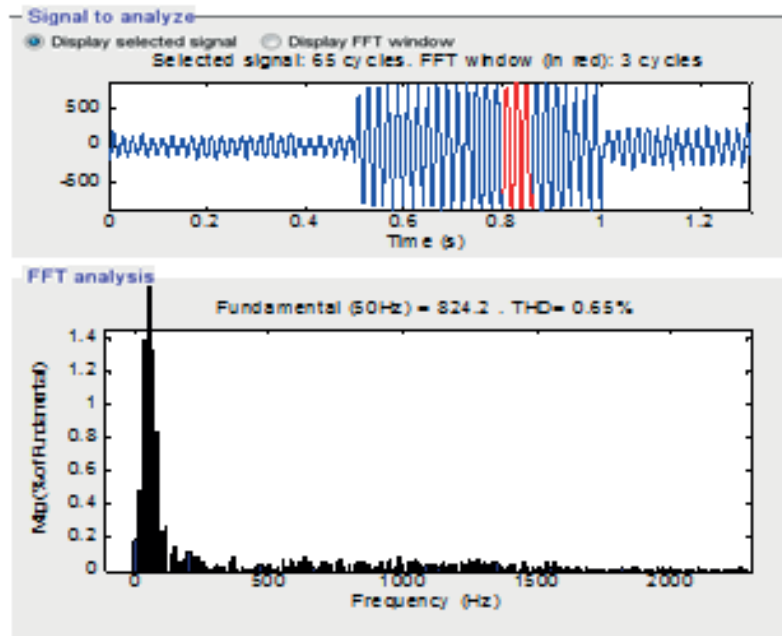

Fig. 15 THD of rotor current for DVC-4L-SVM control (RTT)

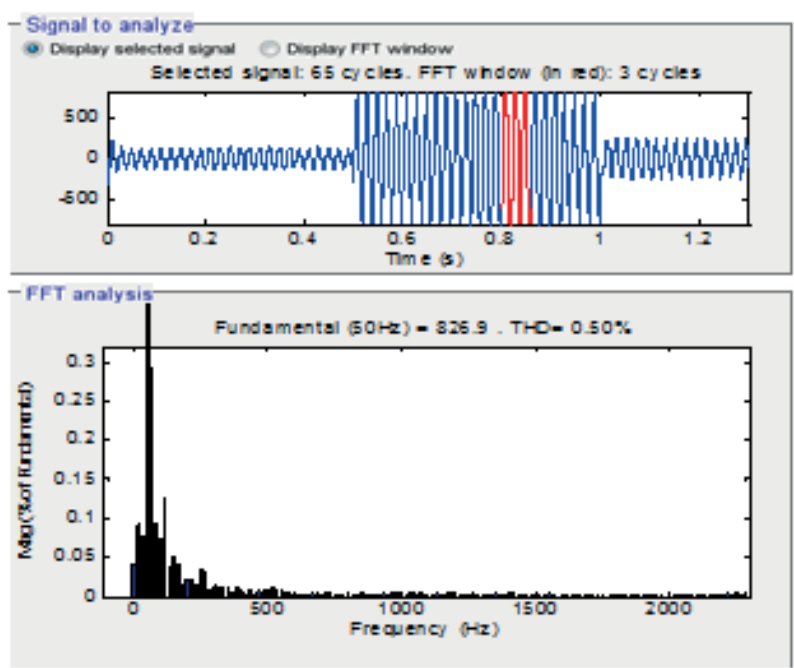

Fig. 16 THD of rotor current for DVC-4L-NSVM control (RTT)

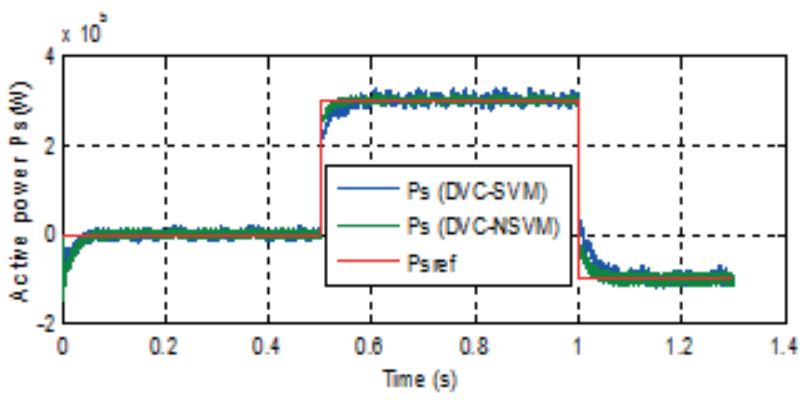

Fig. 17 Active power (RT)

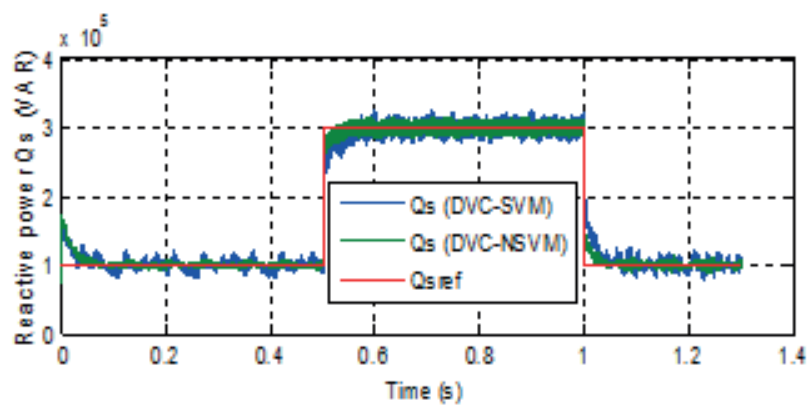

Fig. 18 Reactive power (RT)

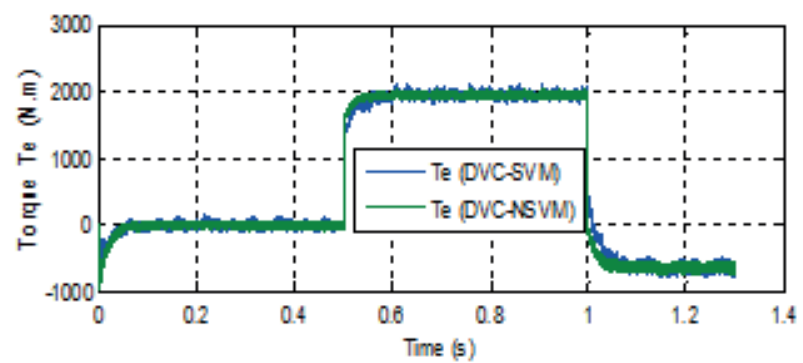

Fig. 19 Torque (RT) 


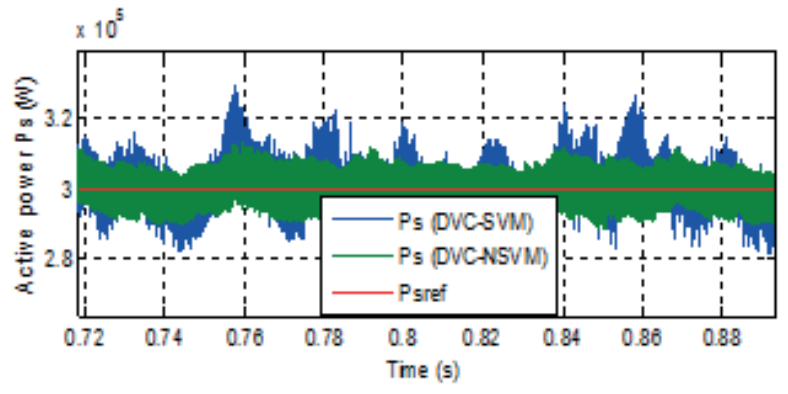

Fig. 20 Zoom in the active power (RT)

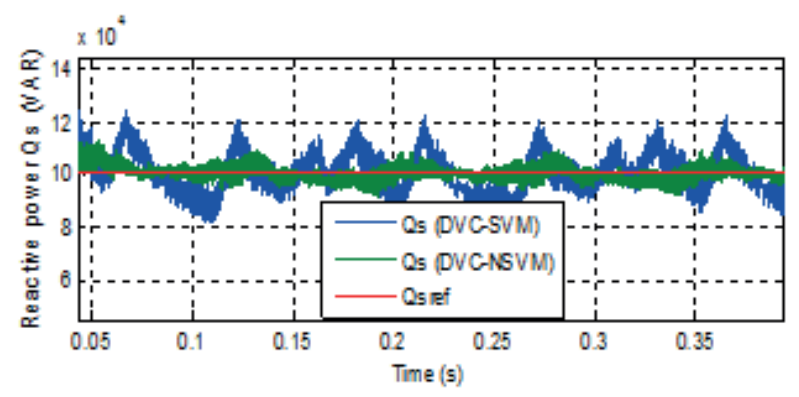

Fig. 21 Zoom in the reactive power (RT)

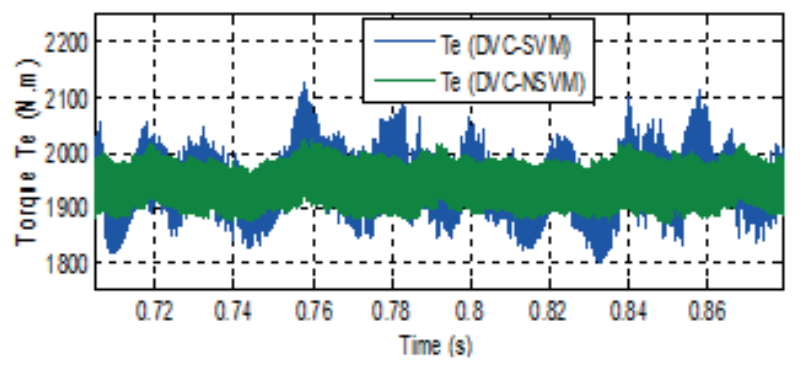

Fig. 22 Zoom in the torque (RT)
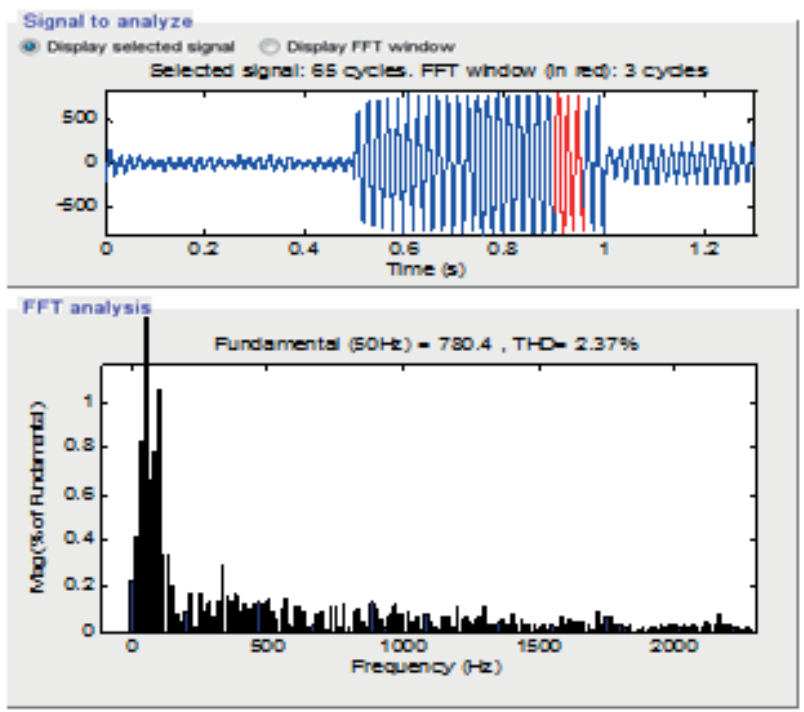

Fig. 23 THD of rotor current for DVC-4L-SVM control (RT)

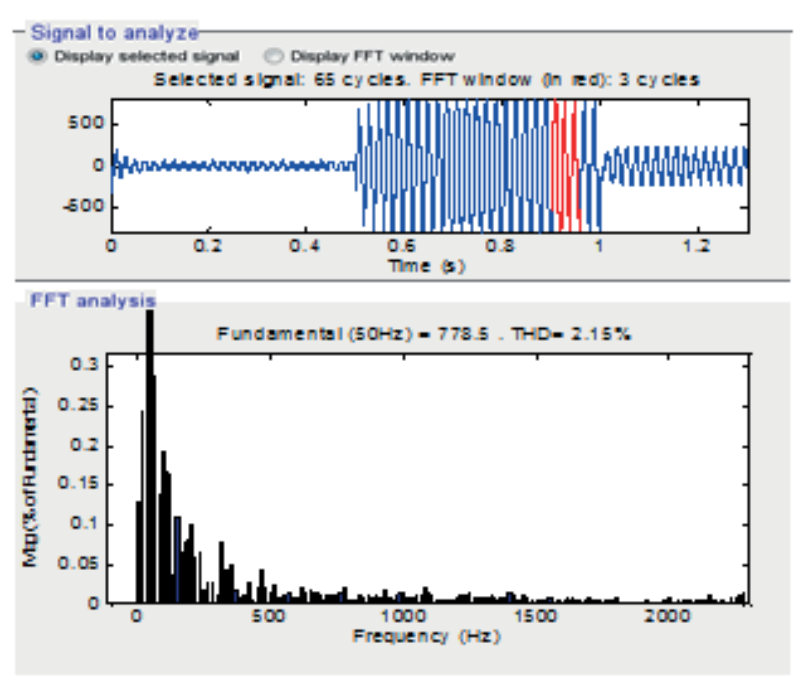

Fig. 24 THD of rotor current for DVC-4L-NSVM control (RT)

Table 3 Comparative analysis of THD value (RT)

\begin{tabular}{lcc}
\hline & \multicolumn{2}{c}{ THD (\%) } \\
\cline { 2 - 3 } & DVC-SVM & DVC-NSVM \\
\hline Rotor current & 2.37 & $\mathbf{2 . 1 5}$ \\
\hline
\end{tabular}

THD value. Thus it can be concluded that the proposed DVC using 4L-NSVM technique is more robust than the DVC using 4L-SVM strategy.

\section{Conclusion}

This work presents a DVC control scheme of a DFIG using a new modulation technique based on four-level SVM and neural networks controller compared with the traditional four-level SVM strategy. The simulation results showthat for similar operation conditions, the DVC control scheme with four-level NSVM strategy presents high-quality performance compared to the DVC control using a four-level SVM technique and that was clear in the THD of rotor current which the use of the four-level NSVM reduces the THD more than the conventional four-level SVM technique. 


\section{References}

[1] Medjber, A., Moualdia, A., Mellit, A., Guessoum, M. A. "Comparative study between direct and indirect vector control applied to a wind turbine equipped with a double-fed asynchronous machine Article", International Journal of Renewable Energy Research, 3(1), pp. 88-93, 2013. [online] Available at: https://ijrer.org/ijrer/index.php/ijrer/article/view/465 [Accessed: 15 October 2018]

[2] Khemiri, N., Khedher, A., Mimouni, M. F. "Wind energy conversion system using DFIG controlled by backstepping and sliding mode strategies", International Journal of Renewable Energy Research, 2(3), pp. 422-435, 2012. [online] Available at: $\quad$ http://www.ijrer.org/ijrer/index.php/ijrer/article/view/249 [Accessed: 10 November 2018]

[3] Hasni, M., Mancer, Z., Mekhtoub, S., Bacha, S. "Parametric identification of the doubly fed induction machine", Energy Procedia, 18, pp. 177-186, 2012.

https://doi.org/10.1016/j.egypro.2012.05.029

[4] Bounadja, E., Djahbar, A., Boudjema, Z. "Variable structure control of a doubly fed induction generator for wind energy conversion systems", Energy Procedia, 50, pp. 999-1007, 2014.

https://doi.org/10.1016/j.egypro.2014.06.119

[5] Kara, Z., Barra, K. "Hybrid Controller for Variable Speed Wind Energy Conversion System with Slip Energy Recovery Using Matrix Converter Topology", Periodica Polytechnica Electrical Engineering and Computer Science, 59(4), pp. 160-174, 2015. https://doi.org/10.3311/PPee.8507

[6] Obdan, H., Ozkilic, M. C. "Performance Comparison of 2-level and 3-level converters in a wind energy conversion system", Revue roumaine des sciences techniques Série Électrotechnique et Énergétique, 61(4), pp. 388-393, 2016. [online] Available at: http://www.revue.elth.pub.ro/viewpdf.php?id=621 [Accessed: 20 November 2018]

[7] Mohamed, E. E. M., Sayed, M. A. "Matrix converters and threephase inverters fed linear induction motor drives-performance compare", Ain Shams Engineering Journal, 9(3), pp. 329-340, 2018. https://doi.org/10.1016/j.asej.2016.02.002

[8] Gaballah M., El-bardini M. "Low cost digital signal generation for driving space vector PWM inverter", Ain Shams Engineering Journal, 4(4), pp. 763-774, 2013. https://doi.org/10.1016/j.asej.2013.02.004

[9] Moghadam, M. A., Noroozian, R., Jalilzadeh, S. "Modeling, simulation and control of matrix converter for variable speed wind turbine system", Iranian Journal of Electrical \& Electronic Engineering, 11(3), pp. 265-275, 2015. https://doi.org/10.22068/IJEEE.11.3.265

[10] Chikhi, A. "Direct torque control of induction motor based on space vector modulation using a fuzzy logic speed controller", Jordan Journal of Mechanical and Industrial Engineering, 8(3), pp. 169-176, 2014. [online] Available at: jjmie.hu.edu.jo/vol\%20 8-3/JJMIE-149-13-01.pdf [Accessed: 20 November 2018]
[11] Benbouhenni, H., Boudjema, Z., Belaidi, A. "Neuro-second order sliding mode control of a DFIG supplied by a two-level NSVM inverter for wind turbine system", Iranian Journal of Electrical \& Electronic Engineering, 14(4), pp. 362-373, 2018.

https://doi.org/10.22068/IJEEE.14.4.362

[12] Benbouhenni, H. "Comparative study between NSVM and FSVM strategy for a DFIG-based wind turbine system controlled by neuro-second order sliding mode", Majlesi Journal of Mechatronic Systems, 7(1), pp. 33-43, 2018. [online] Available at: http://journals.iaumajlesi.ac.ir/ms/index/index.php/ms/article/view/360 [Accessed: 25 October 2018]

[13] Boudjema, Z., Meroufel, A., Bounadja, E., Djerriri, Y. "Non linear control of a doubly fed induction generator supplied by a matrix converter for wind energy conversion systems", Journal of Electrical Engineering, 13(4), pp. 60-68, 2013.

[14] Nazari, A., Heydari, H. "Direct power control topologies for DFIG-based wind plants", International Journal of Computer and Electrical, 4(4), pp. 475-479, 2012. https://doi.org/10.7763/IJCEE.2012.V4.537

[15] Bedoud, K., Ali-rachadi, M., Bahi, T., Lakel, R., Grid, A. "Robust control of doubly fed induction generator for wind turbine under sub-synchronous operation mode", Energy Procedia, 74, pp. 886$899,2015$.

https://doi.org/10.1016/j.egypro.2015.07.824

[16] Senani, F., Rahab, A., Benalla, H. "Modeling and control of active and reactive powers of wind energy conversion system in variable speed based on DFIG", Revue des Energy Renouvelables, 18(4), pp. 643-655, 2015. [online] Available at: https://www.cder.dz/spip. php?article2610 [Accessed: 1 November 2018]

[17] Nwosu, C. M., Oti, S. E., Ogbuka, C. U. "Transient and steady state performance analysis of power flow control in a DFIG variable speed wind turbine", Journal of Electrical Engineering, 68(1), pp. 31-38, 2017. https://doi.org/10.1515/jee-2017-0004

[18] Youcef, D., Meroufel, A., Massoum, A. "Direct power control based artificial neural network of doubly fed induction generator for wind energy conversion systems", Revue roumaine des sciences techniques Série Électrotechnique et Énergétique, 54(1), pp. 1-22, 2009. https://doi.org/10.13140/RG.2.1.2245.2886

[19] Benbouhenni, H. "Seven-level direct torque control of induction motor based on artificial neural networks with regulation speed using fuzzy PI controller", Iranian Journal of Electrical and Electronic Engineering, 14(1), pp. 85-94, 2018. https://doi.org/10.22068/IJEEE.14.1.85

[20] Benbouhenni, H., Boudjema, Z., Belaidi, A. "Direct vector control of a DFIG supplied by an intelligent SVM inverter for wind turbine system", Iranian Journal of Electrical and Electronic Engineering, 15(1), pp. 45-55, 2018. [online] Available at: http://ijeee.iust.ac.ir/ article-1-1238-en.html [Accessed: 15 October 2018] 